\title{
Rib Giant Cell Tumour
}

\author{
Juan C. Collado Otero*, Santiago Quintero and Dagmar Paredes López*
}

National Institute of Oncology and Radiobiology of Cuba, Ciudad Habana, Cuba

\begin{abstract}
A 55 year old woman was admitted because of a slowly growing chest mass. A diagnosis of giant cells tumor (GCT) was made. In sharp contrast to other large bone metaphysis it accounts for $<1 \%$ of all primary rib's neoplasias. The resection included one normal adjacent rib above and below the tumour with all intervening intercostals muscles and pleura and the adjacent cartilages. Reconstruction of the defect in the chest wall required. The standard goal of treatment is surgery and the major prognosis factor is complete resection. Authors consider the rarity location of this entity worth to publish.
\end{abstract}

\section{CLINIC REPORT}

A 55 year old woman was admitted because of a slowly growing chest mass that has been painful for months There were no a history of nicotine abuse or asbestos exposure. On admission there were no pulmonary complaints and physical examination showed only an anterior chest wall mass. With exception of LDH: $1207 \mathrm{U} / \mathrm{L}$; and alkaline phosphatase: 302 $\mathrm{U} / \mathrm{L}$ laboratory results were normal.

\section{RADIOLOGY}

Both chest $\mathrm{X}$ ray and CT scan ( 2 weeks previously) revealed an upper anterior left sided rib mass affecting the second rib and the costochondral junction, with well defined margins, associated cortical erosion and no large soft tissue component projecting into the chest (Fig. 1).

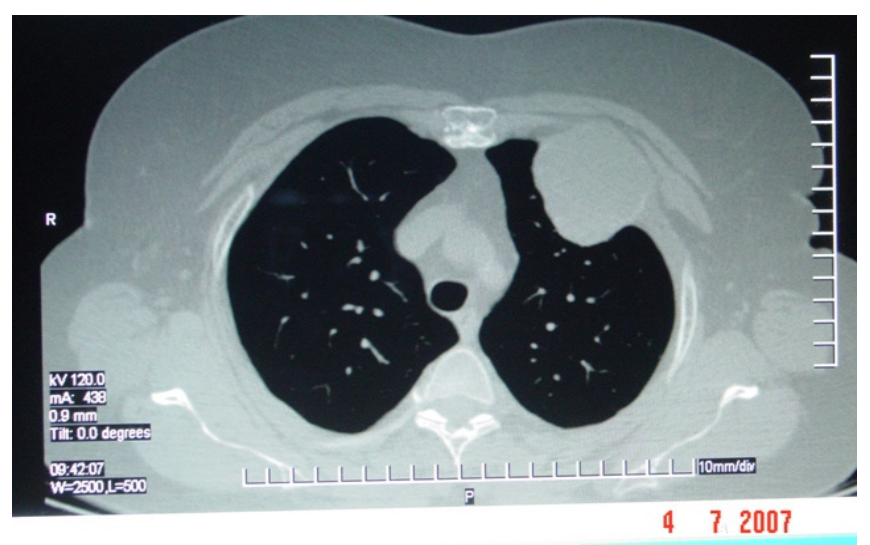

Fig. (1). Upper anterior left sided rib mass, with well defined margins, associated cortical erosion and no large soft tissue component projecting into the chest.

\section{SURGICAL TREATMENT}

As malignancy was suspected, preliminary plans was made for chest wall reconstructions after removal of significant portions of the bony thorax that will allow

*Address correspondence to these authors at the National Institute of Oncology and Radiobiology of Cuba, 29 esq. F Vedado, Plaza de la Revolución, Ciudad Habana, CP: 10400, Cuba; Tel : 83284 15;

E-mail: cinor@infomed.sld.cu,dagmarparedes@infomed.sld.cu resection of a generous margin of normal tissue around the neoplasm. The resection included one normal adjacent rib above and below the tumour with all intervening intercostals muscles and pleura and the adjacent cartilages (Fig. 2).

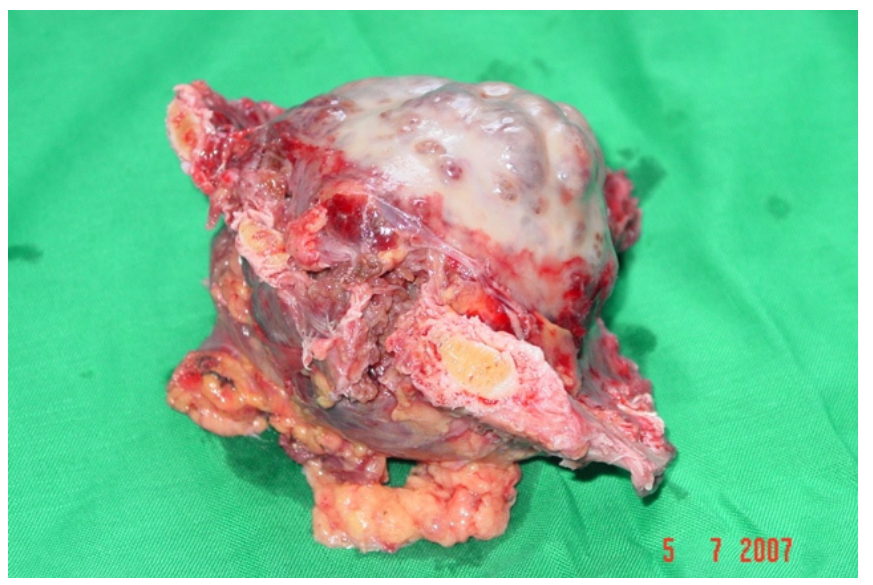

Fig. (2). Surgical specimen including one normal adjacent rib above and below the tumor with all intervening intercostals muscles and pleura and the adjacent cartilages.

Reconstruction of the defect in the chest wall required the use of a double-layer polypropylene (Marlex) mesh sandwiched. A mild degree of paradoxical motion was well tolerated because the area of instability was relatively small. No soft tissue coverage was needed. After an uneventful recovery the patient was discharged home on the third postoperative day. One year postoperatively, there is no clinical or radiological evidence of tumour recurrence.

\section{HISTOLOGIC EXAMINATION}

A diagnosis of giant cells tumor (GCT) was made. (Fig. 3). The morphologic aspects of stromal cells, and the presence of more than 20 mitosis by per ten high power field, express the high grade of this tumour (Fig. 4).

\section{DISCUSSION}

\section{Definition}

Giant cell tumour is a benign, locally aggressive neoplasm which is composed of sheets of neoplastic ovoid 
mononuclear cells interspersed with uniformly distributed large, osteoclastlike giant cells. ICD-O code 9250/1.

\section{Synonym}

Osteoclastoma.

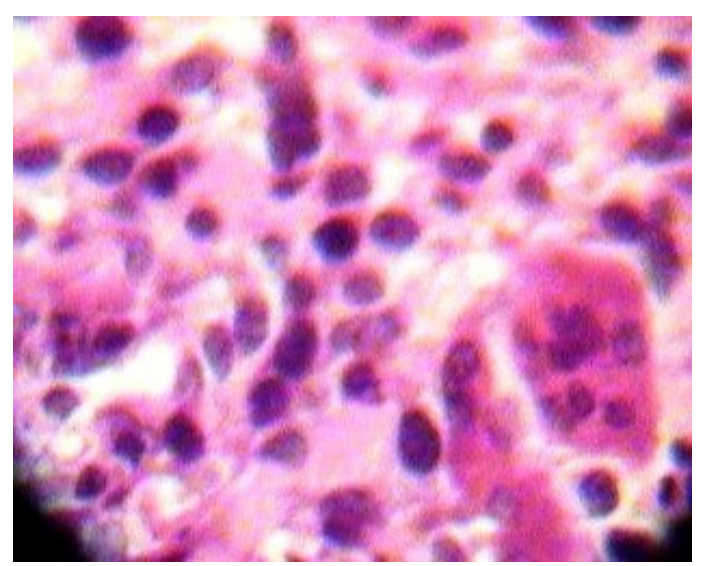

Fig. (3). Morphologic aspects of stromal cells, Giant cell of small diameter is present in the field.

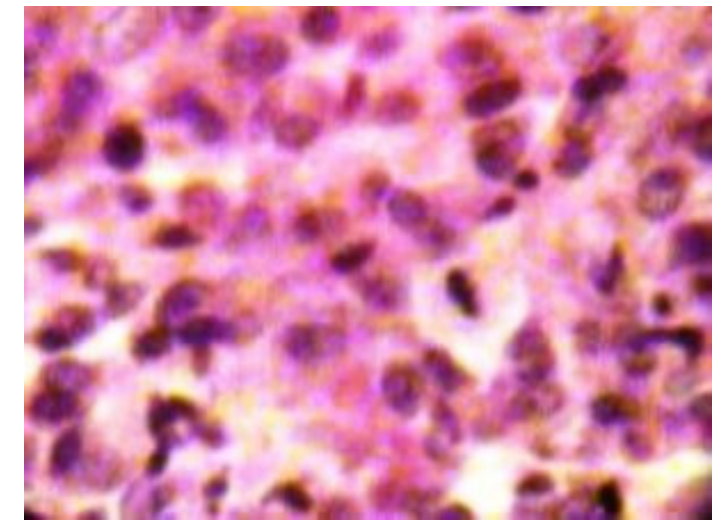

Fig. (4). More than 20 mitosis by per ten high power field, demonstrating the high grade of this tumor.

\section{Sites of Involvement}

(GCT) typically affect the ends of long bones, especially the distal femur, proximal tibia, distal radius and proximal humerus. Around $5 \%$ affect flat bones, especially those of the pelvis. The sacrum is the commonest site in the axial skeleton, while other vertebral bodies are less often involved. Fewer than $5 \%$ of cases affect the tubular bones of the hands and feet [1]

Multicentric giant cell tumours are very rare and tend to involve the small bones of the distal extremities. Malignant change in giant cell tumour is uncommon. A sarcoma may coexist with a giant cell tumour (primary) or may arise at the site of a previously diagnosed giant cell tumour (secondary) [2].

There is seldom much reactive periosteal new bone formation. Only occasionally is radiologically evident matrix produced within the tumour, usually in long standing lesions.
Mitotic figures are invariably present; they vary from 2 to 20 per ten high power fields.

Atypical mitoses are not, however, seen and their presence should point to a diagnosis of a giant cell rich sarcoma. Small foci of bone formation within the tumour are found, especially after pathological fracture or biopsy. Areas of necrosis are common, especially in large lesions. These may be accompanied by focal nuclear atypia which may suggest malignancy [3].

\section{Prognostic Factors}

Histology does not predict the extent of local aggression and histological grading does not appear to be of value in predicting which giant cell tumour will metastasise, providing that giant cell rich sarcomas have been excluded.

The tumour is locally aggressive, but distant metastases are uncommon. When metastases do occur, they rarely prove fatal and hence the term benign metastasis is appropriate.

Pulmonary metastases are seen in $2 \%$ of patients with giant cell tumours, on average 3-4 years after primary diagnosis [2] These may be solitary or multiple. Some of these metastases are very slow growing (benign pulmonary implants) and some regress spontaneously. A small proportion is progressive and may lead to the death of the patient.

Local recurrence, surgical manipulation and location in distal radius may increase the risk of metastasis [3]. True malignant transformation is rare [4] and often follows radiotherapy.

Most of all rib tumours are metastasic on its origin.1. Malignancies represent as many as two third of all primary rib tumours [5, 6]. Rib (GCT) is a subset of primary rib tumors with several unique features. In sharp contrast to other large bone metaphysis it accounts for $<1 \%$ of all primary rib's neoplasias $[5,7]$. It's presentation usually fits one of two patterns: Paget's disease or hyperparathyroidism association. The standard goal of treatment is surgery and the major prognosis factor is complete resection A margin of 1 to $2 \mathrm{~cm}$ of health tissue is recommended [7]. Authors consider the rarity location of this entity worth to publish.

\section{REFERENCES}

[1] Biscaglia R, Bacchini P, Bertoni F. Giant cell tumor of the bones of the hand and foot. Cancer 2000; 88: 2022-32.

[2] Siebenrock KA, Unni KK, Rock MG. Giant-cell tumour of bone metastasising to the lungs: a long-term follow-up. J Bone Joint Surg Br 1998; 80: 43-7.

[3] Masui F, Ushigome S, Fujii K. Giant cell tumor of bone: a clinicopathologic study of prognostic factors. Pathol Int 1998; 48: 723-9.

[4] Marui T, Yamamoto T, Yoshihara H, Kurosaka M, Mizuno K, Akamatsu T. De novo malignant transformation of giant cell tumor of bone. Skeletal Radiol 2001; 30: 104-8.

[5] Sunw HW. Giant cell tumor of bone. J Bone Joint Surg Am 1986; 64: 755-61.

[6] Athanason NA. An inmunohistological study of giant cell tumor of bone. J Pathol 1985; 147: 153-8.

[7] Ocksner A. Tumors of the chest wall. Surg Clin North Am 1996; 46: $1447-52$. 